\title{
Experience of nurse practitioners transitioning into independent practice: A qualitative study
}

\author{
Nicole Twine*1, Sandra Cesario ${ }^{2}$ \\ ${ }^{1}$ Houston Methodist Hospital, Houston, Texas, USA \\ ${ }^{2}$ Texas Woman's University, Houston, Texas, USA
}

Received: October 12, 2018

DOI: $10.5430 /$ jnep.v9n12p41
Accepted: December 26, 2018 Online Published: August 23, 2019

URL: https://doi.org/10.5430/jnep.v9n12p41

\begin{abstract}
Objective: The purpose of this phenomenological study was to explore and describe the role transition of new Nurse Practitioners (NPs) following participation in an internship program with simulated learning to better understand the barriers and facilitators of achieving an autonomous role as an NP.

Methods: In a large academic research medical center in Houston, Texas, purposive sampling was used to recruit a sample of 14 acute care NPs who had recently participated in a pre-graduate internship program. Demographic data were collected and in-depth, one-on-one interviews were conducted using a semi-structured interview guide. The interviews were audio-recorded and transcribed verbatim. Colaizzi's process for phenomenological data analysis was used.

Results: Four themes emerged from the analysis of the interviews: Putting on My NP Shoes, which described the participants' statements about progression in their new role; We're Only as Good as We Train, which described the participants' statements about how NPs are trained to practice compared with other professionals; My Internship Prepared Me, which described how additional education and exposure to an internship program prepared the participants for entry into practice; and Relationships Provided Success, which described the participants' statements about building collaborative relationships with physicians and staff that impacted their transition.

Conclusions: The findings from this phenomenological study will provide knowledge to develop or adapt educational programs for NPs and to further develop internship or postgraduate residency programs for advance practice nurses.
\end{abstract}

Key Words: Nurse practitioner, Role transition, Transition experience, Advance practice nurse, Transition programs

\section{INTRODUCTION}

In today's rapidly changing health care field, the demand for nurse practitioners (NPs) is high. Over 26,000 new NPs completed their academic programs in 2016-2017. More than 248,000 NPs are currently licensed in the United States, $86 \%$ of whom are prepared to deliver primary care and secondary care. ${ }^{[1]}$ In early 1990 s there were perceived gaps in our healthcare delivery due to changes in medical residents work hours, so the Acute Care Nurse Practitioner (ACNP) role was created to fill those gaps. Over the past 20 years the number of ACNPs has grown to approximately 20,832, with over $60 \%$ of their care being delivered in a tertiary environment. $^{[1]}$

As health care reform continues to evolve, NPs will be key stakeholders in improving the care of complex patients. This increases the need for NPs who can perform at a higher level and will require NPs to possess skills that provide them with expertise in assessment, communication, and critical thinking, which are integral to safe and effective patient care outcomes. $^{[2]}$ A projected shortage of 52,000 practitioners

*Correspondence: Nicole Twine; Email: nltwine2@ houstonmethodist.org; Address: 6565 Fannin, Houston, Texas 77030, USA. 
is expected by 2025. ${ }^{[3]}$ Advance practice providers such as NPs can provide care services of quality equivalent to that provided by physicians and on a more cost-effective basis. ${ }^{[3]}$ For NPs to fill the gap sooner, their educational preparation is key.

The transition from student to professional NP is an important and difficult adjustment. The presence and quality of transition programs are rare, yet new NPs report the need for additional support and education as they move from being students to practicing NPs. An actual transition period new graduates undergo as they enter into NP practice has been determined by several researchers. ${ }^{[4]}$ The new role as a NP is one in which there is more autonomy and advanced decisionmaking. Learning environments that support critical thinking and synthesis of information are known to facilitate role transition. ${ }^{[5]}$ Acquiring quality effective education to function in the NP role is the initial stage in the transition from a student NP to an independent NP.

\subsection{Literature review}

A literature search using CINAHL and PubMed identified studies that focused on establishing the role and transition of new NPs into practice. The search was limited to Englishlanguage and peer-reviewed journals. The search range was restricted to a 10 year time frame, but due to limited literature it was expanded to 20 years. Analysis of the literature revealed three topic areas that had influence on NP transition: transition into the new role, adequacy of preparation, and challenges faced with transition. For example, Heitz et al. ${ }^{[6]}$ revealed that the role transition from registered nurse (RN) to FNP (family nurse practitioner) occurs in 2 phases. The educational process is when the first transition phase begins. The second phase is transition into the role from graduate to independent FNP. This transition phase occurs during the first 6 months up to 2 years after graduation. ${ }^{[5]}$ The NPs in the study by Brown \& Olshansky ${ }^{[7]}$ described the transition experience as an adjustment period that was often difficult They felt like imposters as if they were "faking it", and had difficulty "feeling real." The transition from the expert RN to a novice NP during this adjustment period was described as difficult to make.

Various studies evaluated the NPs' perception of training. Jones et al. ${ }^{[8]}$ explored NP graduate perceptions of adequacy of their education in preparing them to provide effective care to the aging population. In Jones et al., ${ }^{[8]}$ more exposure to meaningful clinical education was described as significant by theses graduates. NPs felt there was a lack of preparation and reported they would have been open to additional structured training. They often relied heavily on their past nursing experience to fill gaps in their knowledge. Hart and Macnee ${ }^{[5]}$ revealed that NP educational programs do have structured accredited curricula but lack the ability to provide robust opportunities for clinical exposure. The findings revealed, programs that could provide students more clinical hours while reinforcing the key concepts for health care delivery would be welcomed by the NPs. ${ }^{[5]}$ Harris $^{[9]}$ found a need for more didactic content and clinical experiences specific to the care of older adults. The adequacy of preparation into practice was reported as not feeling equipped, a desire for additional training, and consistently using prior nursing experience to fill knowledge gaps.

An emerging issue in literature that impacted the transition process was creating collaborative relationships and providing effective mentorship opportunities. Dillon et al. ${ }^{[10]}$ revealed that support from physician or NP mentor was deemed important. Lack of support hindered their process. Building new relationships with coworkers and the unfamiliarity with the role of the NP by patients was perceived as a challenge in the literature.

Establishing one's role as an NP, creating collaborative relationships, and having effective mentorship were identified as crucial influences in the transition process of the new NP. The educational preparation and clinical exposure were recognized as the foundation in the transition process and was viewed as the key stage in the transition from student to independent NP.

\subsection{Purpose}

The purpose of this phenomenological study was to explore and describe the transition of new NPs to their role after they participated in a 1-year pre-graduate student NP internship with a goal to better understand the barriers and challenges faced by nurses in the transition to reach the autonomy of new Nurse Practitioner.

Phenomenology is the study of human experience from the perspective of those experiencing a particular phenomenon. Husserl believed that subjective information should be important to scientists seeking to understand human motivation because human actions are influenced by what people perceive to be real. ${ }^{[1]}$ The knowledge gained by exploring the experience of NP students from a descriptive phenomenological perspective will provide educators with new information to apply to further develop training programs for advance practice nurses.

\section{Methodology}

\subsection{Overview of the study}

Husserl's descriptive phenomenological approach was used to explore the experience of new NPs during their transition 
to independent practice. The data collection process began after approval from the institutional review board (IRB) at Texas Woman's University and the clinical agency. Completion of a pilot study further informed the process. The overarching research question that guided this study was: What is the experience of new NPs during their transition to independent practice after they participated in a student internship with simulated learning? Semi-structured questions were used to facilitate examination of the participants' experiences.

\subsection{Setting and sample}

The setting of the study was a large academic hospital in Houston, Texas. The location was mutually agreed upon by the researcher and the participants.

Participants were ACNPs who had completed a pre-graduate NP internship program and had a minimum of 3 months of NP experience and up to a maximum of 1 year of experience. They had to be board-certified and actively working in a NP role. We used purposeful sampling to identify prospective participants. This allowed us to select individuals who could offer insight into the phenomena being investigated. ${ }^{[12]}$ After the researcher interviewed the first 12 participants who met the inclusion criteria, no new information was yielded after 12 interviews. The researcher confirmed data saturation by interviewing 2 more participants.

Participants were master's prepared, board-certified ACNPs who participated in the internship program Leading Education and Advancing Professionals (LEAP). All participants had bachelor's degrees as their basic education, had attended a traditional BSN-to-MS program, and attended school on a part-time basis. Participants worked as RNs while attending graduate school. All participants were currently employed as ACNPs. Of the 14 participants in the study, 1 was a man and 13 were women. According to the National Council of State Boards of Nursing, ${ }^{[13]}$ women dominated the nursing profession before 2000, at which time $5.8 \%$ were male, whereas of those licensed between 2013 and 2015, 14.1\% were male.

The ages of the participants ranged from 25 to 44 years. According to the American Academy of Nurse Practitioners, ${ }^{[1]}$ the average NP is female (96\%), 48 years old, and has been practicing as a FNP for 12.8 years. Furthermore, 5.6\% are ACNPs and have been in practice for 7 years. ${ }^{[1]}$ The participants reported a range of years licensed as an $\mathrm{RN}$ as 4 to 18 years, with the average number of years of $\mathrm{RN}$ experience being 8 years. Of the 14 participants, 3 participants had 10 or more years of experience as an RN before obtaining their NP license. Eight participants had worked as an RN in the same hospital before becoming an NP. Three participants were the first NPs used in their particular service or unit. Seven of these participants began their NP role in the same clinical specialty in which they had initially worked as an RN. The participants had a diverse ethnic makeup: $36 \%$ were African American, $22 \%$ were Asian, and $43 \%$ were white. A total of $14 \%$ had received undergraduate nursing training outside the United States. Five students had attended online NP programs and 9 students had attended a local 4-year university with a traditional classroom model (see Table 1).

Table 1. Demographic data of the study participants $(\mathrm{n}=14)$

\begin{tabular}{|c|c|}
\hline Variable & Value \\
\hline Age, year (range) & $25-44$ \\
\hline Prior RN experience, year (range) & $4-18^{*}$ \\
\hline \multicolumn{2}{|l|}{ Prior leadership exposure, \% } \\
\hline Prior charge nurse experience over 2 years & 95 \\
\hline \multicolumn{2}{|l|}{ Prior nursing experience, \% } \\
\hline Prior ICU specialty experience & $57^{\dagger}$ \\
\hline Prior cardiology specialty experience & $29^{\ddagger}$ \\
\hline Procedural area experience & 14 \\
\hline \multicolumn{2}{|l|}{ Race, \% } \\
\hline African American & 36 \\
\hline Asian & 33 \\
\hline White & 43 \\
\hline \multicolumn{2}{|l|}{ Gender, n (\%) } \\
\hline Female & $13(93)$ \\
\hline Male & $1(7)$ \\
\hline \multicolumn{2}{|l|}{ Current NP experience, n (\%) } \\
\hline 1 year & $4(29)$ \\
\hline 6-9 months & $5(36)$ \\
\hline 3-6 months & $5(36)$ \\
\hline \multicolumn{2}{|l|}{ Type of NP program, n (\%) } \\
\hline Online NP program & $5(36)$ \\
\hline Traditional NP program & $9(64)$ \\
\hline \multicolumn{2}{|l|}{ New NP role, n (\%) } \\
\hline Worked in same facility as new NP & $8(57)$ \\
\hline The first NPs used in their service lines & $3(21)$ \\
\hline Work in the same prior RN specialty & $7(50)$ \\
\hline
\end{tabular}

\subsection{Protection of human subjects}

Consent to participate in this study was obtained from all participants. Participants were given an opportunity to ask questions before being asked to sign the informed consent. All files with identifiable information were locked in a secure cabinet that only the primary investigator had access to. Reports of findings did not include any identifying information.

\subsection{Data collection}

After informed consent was obtained, a flyer asking the participants to contact the investigator if interested was sent out via email. Contact was made via phone to discuss interest in 
the study. After the participants were recruited, they were emailed and telephoned to set up individual interview dates and times. Participants met at mutually agreeable dates and times. The interviews took place at the researcher's office. Before the interview, the participants were provided the in formed consent document to read, were given the opportunity to ask any questions, and signed the document. Participants were told they could stop the interview at any time and their anonymity would be upheld. They were assigned a code to maintain their confidentiality. Following the signed consent, each participant was given a demographic questionnaire to complete.

Table 2. Semi-structured interview guide

Questions
1. Tell me about an experience that stands out as an example of
your transition into NP practice.

\section{Describe your new hire orientation.}

3. Describe the first time you had to take care of a critical patient.

4. How did the internship program affect your transition into NP practice?

5. How did the simulation training affect your transition into NP practice?

6. Tell me about your experience with other professionals.

7. What advice do you have for modifying the internship program?

8. Describe how the internship supported your prior nursing experience.

9. What advice do you have for student or newly graduated NPs?
Once the consent was signed and the demographic form was complete, the researcher turned on the audio tape to record the interviews. Each interview time averaged 40 to 45 minutes. The researcher anticipated 20 respondents; 17 responded to the letter of invitation. The data were collected over a period of 4 months from January 2018 to May 2018. The investigator conducted semi-structured interviews using an interview guide (see Table 2). Throughout the entire interview session, the researcher observed no emotional distress or hesitation in responses. The participants were engaged and very open in sharing their experiences.

\section{Probes}

a) What was helpful in your transition?

b) What made your transition difficult?

c) Describe an experience that was different. What made it different?

a) What prepared you for your new role?

a) What do you think went well?

b) What didn't go well?

c) What do you feel prepared you to manage the situation?

d) Why do you feel you were not prepared to handle the situation?

a) How did the internship program help?

b) How did the internship program make it more difficult?

a) What was positive?

b) What was negative?

a) How have other professionals influenced your transition to practice?

a) What would you change?

b) What would you add?

a) How did it build up on your experience?

\subsection{Analysis}

Descriptive statistics were used to calculate frequencies and percentages for the demographic data collected. Audio recordings were transcribed verbatim by a secure transcriptionist service and were verified by members of the research team. Colaizzi's descriptive process for phenomenological data analysis was used. ${ }^{[14]}$ After each interview was transcribed, the transcript was read and re-read to obtain a general sense of the content. Significant statements pertaining to the research question and the phenomena being studied were extracted. The statements were recorded on a separate sheet, noting the pages and line numbers of the original transcription. Significant meanings were extracted from the significant statements, and 4 overarching themes were identified, with the goal of describing the phenomenon of the transition experience.

\subsection{Scientific rigor}

Establishing scientific rigor is important for robust and unbiased experimental design, methodology, and analysis. Established standards of rigor were used (credibility, transferability, dependability, and conformability) to enhance the trustworthiness of the process. ${ }^{[15]}$ Trustworthiness was established by ensuring validity and reliability throughout all stages of data collection and data analysis. ${ }^{[16]}$ The investigator worked to ensure the findings were reasonable, accurate, consistent, and detailed enough to approximate the experi- 
ence. The principal researcher had to identify and bracket personal assumptions and biases. Bracketing is used to alleviate the potentially harmful effects of preconceptions that may taint the research process. ${ }^{[17]}$ Bracketing was considered throughout the entire research process, not just at the data collection and analysis phases. ${ }^{[17]}$ Before the start of the research study, the researcher wrote down what is known about the topic and the perceived issues, thereby bringing them into consciousness. $^{[18]}$ Revisiting these throughout the project ensured that the investigator's ideas did not override those of the participants. Following strategies to achieve bracketing, the primary researcher also kept a reflective journal to document thoughts, feelings, and perceptions throughout the research project. Developing an audit trail also provided a framework for establishing trustworthiness.

Validation included clarifying the data with the participants to establish the accuracy of the researcher's interpretation. Dependability was established by using detailed journaling, detailed written field notes, memos, taped semi-structured interview sessions, and reflective journaling. Confirmability was achieved by the logical order of data analysis and interpretation. To establish confirmability, an audit trail began when the study was designed and was maintained throughout the study. ${ }^{[16]}$ Audit trails document the course of the study from development through the completed analysis. In developing an audit trail, the investigator provided an account of research decisions and activities throughout the study. The goal was to establish transferability for the reader by providing a thorough description of the participants, the research framework, and the assumptions central to the research. ${ }^{[16]}$

\section{Findings}

Four themes emerged from the analysis of the interviews (see Figure 1). The themes were as follows: Putting on My NP Shoes, which described the participants' statements about progression in their new role; We're Only as Good as We Train, which described the participants' statements about how NPs are trained to practice compared with other professionals; My Internship Prepared Me, which described participants' statements about how additional education and exposure to an internship program prepared them for entry into practice; and Relationships Provided Success, which described participants' statements about building collaborative relationships with physicians and staff and how these relationships may have impacted their transition.

\begin{tabular}{|c|c|}
\hline Themes & Subcategories \\
\hline Putting on My NP Shoes & $\begin{array}{l}\text { Describes participants' statements about progression in } \\
\text { their new role } \\
\text { - Establishing identity was easier } \\
\text { - Experienced many emotions } \\
\text { - Modeled behaviors } \\
\text { - Surprised with growth }\end{array}$ \\
\hline We're Only as Good as We Train & $\begin{array}{l}\text { Describes participants' statements about how NPs are } \\
\text { trained to practice compared with other professionals } \\
\text { - Gaps in communication } \\
\text { - Gaps in developing differential diagnosis } \\
\text { - Lack of preparation in medical model } \\
\text { - Feeling of inadequacy }\end{array}$ \\
\hline My Internship Prepared Me & $\begin{array}{l}\text { Describes participants' statements about how additional } \\
\text { education and exposure to an internship program prepared } \\
\text { them } \\
\text { - Increased self-confidence } \\
\text { - Increased clinical exposure/simulation training } \\
\text { - Enhancement of professional role development }\end{array}$ \\
\hline Relationships Provided Success & $\begin{array}{l}\text { Describes participants' statements about building } \\
\text { collaborative relationships with physicians and staff } \\
\text { - Understanding expectations } \\
\text { - Developing effective communication } \\
\text { - Identifying mentors } \\
\text { - Respecting staff and colleagues }\end{array}$ \\
\hline
\end{tabular}

Figure 1. Four themes identified in the experience of nurse practitioners transitioning into independent practice 


\subsection{Putting on My NP shoes}

This theme revealed changes in the participants' identity and expertise. Participants described the experience of having been an expert RN as they faced being a novice NP graduate. Role identity was described. All participants anticipated dealing with changes in their role and identity, and they experienced a series of emotions as they transitioned. Some participants revealed that establishing their identity as a provider was easier because they were given an opportunity to model behaviors after their NP preceptors. However, they still expressed that role transition was something they had to deal with even though they had pretty good insight into the NP role and the expectations of the role. Participant 2 stated, "I was still trying to separate being a clinical bedside nurse to my new role." At three months of experience, to say that I'm an NP... it was hard to get that word out.

Participant-6 stated, "In the beginning it was just realizing that I was the person... I needed to step up..."

The participants expressed various emotions such as fear and anxiety. The need to do well and perform at the provider level was very important, especially with the new level of responsibility they had acquired.

Participant 10 stated, "I felt kind of lonely. I'm like, I'm really the only NP that's managing. No one else is going to be seeing this patient with me."

As time went on, several participants described they were able to see their growth as they gained more time and exposure in their new NP role. At 9 months into practice, Participant 4 stated, "Today I feel good. I feel like I am equipped with the tools, and the knowledge, and the resources that I need in order to really take care of my patients safely." Another participant who had only a couple months of experience stated, "I never thought I would have grown to be this type of a provider by now. I've surprised myself and that sometimes is scary... the responsibility, it gets bigger and bigger every day."

The participants described many experiences that have been discussed in literature in regards to NP transition. They frequently expressed being ready to take on more quickly and felt confident to function at a higher level sooner than they would have expected.

\subsection{We're Only As Good As We Train}

This second theme emerged from the participants' accounts of their feelings of a lack of clinical preparation in graduate programs compared with those for physician assistants (PAs). There is an expectation to perform at a certain level, and statements were made that PA and NP training was very different. The participants described using prior nursing ex- perience to fill the gaps. They expressed that they felt PAs had an advantage because they were prepared to evaluate patients in more of a medical model, which allowed them to communicate and think differently about patient cases. This was supported by recommendations from participants that an internship training program in addition to graduate school is needed to help support NP training.

Participant 4 stated, “...We are expected to work kind of like residents and fellows, but we're not brought up like them..... the biggest challenge I've had, is learning how to communicate like a doctor in a way they can understand what I'm trying to say."

Participants expressed concerns that their didactic training and preparation in graduate NP programs was not the same as in other provider graduate programs. Many described not being prepared in the medical model, and they felt a lack of focus on pathophysiology in developing differential diagnoses in their graduate programs was an obstacle.

Participant 3 stated, "I also think that physicians and PAs are better prepared than we are in pathophysiology.... I think they have an advantage over their medical training than we do".

\subsection{My Internship Prepared Me}

This third theme evolved from the participants' accounts of how they felt the internship program impacted their transition into practice. Some participants revealed there was an overall increase in self-confidence when starting their new NP role. NP participants described a clear sense of independence of the initial foundational skills a NP should have when entering practice. There was an overall belief they were getting additional or special training their colleagues did not have. The participants expressed that increased clinical exposure, frequent simulation training, and opportunities to enhance their professional role development were a large part of their transition experience. Participant 11 stated, "It depends on how great your clinical experience was...you know, not everyone allows you to be as hands-on. But with the LEAP program, I was practicing as an NP. I wrote orders. I saw patients. I wrote notes. So that helped the transition. I mean, just using the EMR system as a provider was huge, because I know how to find stuff. I know how it works."

\subsubsection{Clinical exposure}

The participants in this study completed an additional 1,0001,250 clinical hours participating in this program. With the additional clinical rotations provided by the internship in addition to their required graduate program hours the participants described being more prepared and comfortable to manage new patient scenarios in their NP role. 
Participant 5 stated, "Being in the LEAP program I think has made me more confident... being exposed to more things in addition to clinical... managing different patient populations, more in-depth discussion with my preceptors, learning about different diagnoses or diseases that may have not been covered in my program."

This participant fell she was taught in the nursing model to manage patient so exposure to additional training helped in her transition. She stated, "All these little things helped me transition a lot easier and I think having the LEAP program built a lot of confidence coming out of the program versus never being in a provider role independently and then just showing up on the floor managing patients". The participants had a recognition of how they improved their communication with patient's, families and providers. The ability to discuss complicated patient situations and practice and hone skills in safe place gave them an opportunity to practice all type of scenarios without fear of making detrimental mistakes.

Participant-1 stated, "The education I've gotten in school was to get me to pass my exams and to teach me how to be a nurse practitioner, but it didn't teach me how to actually practice and how to manage the patient...

Participant 5 stated, "People here helped me to see, talk to the patients and family, I know how to explain to the family, give the update and input of what we're testing."

\subsubsection{Simulation training}

The participants were exposed to monthly simulation that allowed for immediate feedback. Some participants felt their clinical decision-making was easier due to more hands-on exposure to the NP role and frequent simulation scenarios, although the situations were sometimes intimidating. Several participants expressed that the scenarios did not always appear as real patient situations. However, the exposure to frequent simulation cases helped them be better prepared for real patient situations.

Participant 5 stated, "Took me a while to think through the scenario and make my decision... Now those things that I missed in simulation will be the first things to do in a real life."

Participant 6 stated, "I am still drawing on those experiences and exposure that I don't think... I wouldn't have had in school..."

\subsubsection{Professional role development}

The participants described other professional opportunities in addition to their clinical education that they were exposed to. They believe being exposed to different facet of the NP role such as presenting information to their NP Peers presen- tation completing quality improvement and evidence based practice projects impacted their transition into the new NP role as well.

Participant 11 stated, "The exposure to different areas was very helpful... it actually really prepared you for the NP role... it helped you build your portfolio and resume. We had to take different classes, FCCS, keeping up your certifications, going to conferences. We had to do evidence-based practice, which you will be doing as an NP."

\subsection{Relationships provided success}

The fourth theme emerged as the participants described how important it was for them to have collaborative relationships with colleagues. Most of the participants shared that a supportive relationship with the primary physician was crucial to having a positive role transition in the hospital. Those who described physicians positively used such words as "great," "amazing," "open to teach," "available," and "colleague." Most of the participants expressed that the internship program helped them know the expectations of physicians and hospital administrators.

Participant 2 stated, "I think the physicians were great because they're willing to teach and explain things. Participant 6 stated, "My current MD is very supportive... We're like colleagues..."

The participants described that effective communication techniques were developed during their internship experience with physicians, nurses, and staff. This was believed to have impacted their transition into practice. Several participants described exposure to different types of providers and different styles of collaborative working relationships that influenced their current work relationships, which helped them forge collaborative relationships with physicians, staff, and hospital administrators. Every participant spoke about the impact of these relationships.

Participant 3 stated," I'm lucky to practice with physicians who are not only great clinicians, but also great collaborators and they allow for autonomy within reason.

Participant 5 stated, "My mentor was a physician, so that was something new to me, because I always did my clinicals with nurse practitioners."

Participant 4 stated, "I think if my attending were punitive. Questioning my skills, not trusting me to take care of their patients, I wouldn't feel comfortable to practice. I think I would be apprehensive..."

Participants also recognized that developing relationships with nursing staff was key. Although they gained new authority, they understood that treating the staff as a resource 
would only provide better patient outcomes.

There was acknowledgement that there should be a mutual understanding and respect for each other's role because it has an impact on patient's care and outcomes.

\section{SUMMARY}

This study provided qualitative findings from in-depth, oneon-one interviews with 14 participants. Through the analysis of the data, 4 themes emerged that described the participants' lived experience regarding their transition into NP practice. These themes provide a framework for understanding the transition experience after participation in an internship program.

Participants described many experiences that have been discussed in the literature with regard to NP transition. The participants did experience a transition phase, although many felt their transition phase was of a shorter time frame. The 14 participants were at different stages and months of experience when interviewed. Five of the participants had 3 months of experience, 4 participants had between 6 and 8 months of experience, and 5 participants had 9 months to 1 year of experience.

Graduates at 3 months described feeling more prepared than the average NP transitioning into practice. These novice NPs still expressed some anxiety; however, they described that having exposure to the NP role in their internship decreased the unknown about that role and what their new identity as a NP would be. One participant stated, "I feel like that I've made that transition into my role... I'm working alongside a new NP and I feel like because of this LEAP program that I'm ahead of the game. Things come a lot easier to me than they do for her." Graduates at 6 months to 1 year described more self-confidence. One participant stated, "I feel like I am equipped with the tools, and the knowledge, and the resources that I need in order to really take care of my patients safely." There was overall recognition of the progress made but acknowledgement and surprise about how much further they were than their colleagues who did not participate in an additional training program.

According to Brown and Olshansky, ${ }^{[7]}$ there is a transition period as NPs enter into practice. This first year is considered to be the most important of the transition phase from $\mathrm{RN}$ to NP. ${ }^{[7]}$ The review of current literature revealed that during this transition period, many NPs report finding it difficult to make the transition from an experienced $\mathrm{RN}$ to a novice NP. The participants in the study believed the internship program helped their transition experience into practice because they described feeling more prepared to manage patients more independently sooner because of the additional training time spent developing skills. More self-confidence to make decisions autonomously was partly because of the additional hands-on training. The participants indicated that establishing their identity as a provider was easier because they were able to model their behavior after their NP preceptors and they had a year to practice in the NP role. Hart and Macnee ${ }^{[5]}$ reported that $10 \%$ of new NPs felt they were adequately prepared for entry into practice after completing their NP education. Fifty-one percent felt somewhat or minimally prepared. Thirty-eight percent believed that they were mostly well prepared. Participants in the study expressed a desire for a more rigorous NP education, including more clinically relevant information and more proficient faculty. When asked, Did your training prepare you for practice? the internship was believed to have played a large part in preparation. However, there seemed to be an overwhelming perception of difference in training between PAs and NPs. Utilization of prior nursing experience was often used to fill gaps in their standard graduate training. There was an overwhelming perception that PAs had an advantage because they are prepared to evaluate patients in more of a medical model, which allowed them to communicate and think differently about patient cases.

The internship was credited for the participants' improvement in communication with physicians and other allied health providers because of the significant time spent providing high-quality care while collaborating with various interdisciplinary team members. They learned how to differentiate between ineffective and effective ways to communicate with staff to foster better working relationships. This was attributed to spending additional time in the training role. The simulation experience throughout the internship was viewed as a positive experience. Bays et al. ${ }^{[18]}$ found that training physicians and NPs via small-group simulations showed "significant improvement in trainees' ability to communicate bad news and express empathy."

Simulation allowed the participants to develop the skills needed for differential diagnosis and to practice these skills in changing patient condition scenarios in a safe, controlled learning environment. Simulation was used to build on previously learned skills and provided comfort for the NP to make independent decisions. The participants did acknowledge it was more training than some of their classmates received, and they felt that more clinical exposure and simulation training would have been ideal.

\section{Recommendations}

Nursing educators can use these findings to identify opportunities to develop or restructure NP curricula that will complement current graduate programs and entry into practice 
requirements. Our findings imply an opportunity to consider changes to the NP curriculum in the final semesters that focus on unique training to better support the new NP. By participating in this program an additional 1,000-1,250 clinical hours was obtain. Strategies' to supplement current program structures by revaluating didactic and hands on clinical exposure should be explored.

The findings suggest that many hospital institutions do not have a structured orientation to onboard new NPs. NPs may participate in the bedside nursing orientation or they may be expected to follow a practice physician without structure. Trying to fit the new NP into these existing processes may be inadequate for readying them for their new role. Inadequate preparation for practice could result in a transition that is delayed or possibly unsuccessful.

A key component of how these NP participants transitioned revolved on their feeling adequately prepared to function at a basic level. The additional time spent training to provide that level of care gave them more time and exposure before entering into independent practice. The NP participants also described inconsistent experiences regarding their clinical experience. An organized training structure was ideal to build on their foundation. Most of these participants had hospital-based clinical rotations as a student, but some felt it difficult to get a robust clinical exposure. This was partly because of a lack of NP preceptors or the right providers with clinical experience or the desire to develop and train them.

With the increasing number of online NP programs, the participants who completed their education through a nontraditional format expressed even more of a benefit to their transition. Although they were enrolled in ACNP programs, most of their prior nursing experience was in an ambulatory setting, and their particular online programs did not have structured hands-on clinical experience as part of the graduate program. Most online programs had limited faculty resources to assist in their training, which required them to seek out their own training.

The average NP program requires 500 to 600 clinical hours depending on state requirements before entry into practice. The participants recommended extending clinical hour expectations for NPs either by increasing hours for graduate programs or by creating more transition programs, such as internships or postgraduate programs. Many of the participants expressed that the internship was a great benefit, but also felt that there still was not enough exposure to the medical model of managing patients. They did not want to lose the holistic approach and preparation of being a nurse but they did not feel that their graduate programs truly prepared them for the new role.

\section{Conclusion}

As our health care delivery model continues to reform, NPs will continue to play key roles in improving health outcomes of diverse populations. According to the Institute of Medicine (IOM) 2011 report The Future of Nursing: Leading Change, Advancing Health, nurses should be change advocates by caring for populations within complex health care systems. ${ }^{[19]}$ The IOM reports states, "advanced practice registered nurses (APRNs) should be able to practice to the fullest extent of their education and training." ${ }^{[19]}$ This research addresses that need by providing information that can influence the development of nursing curricula. Ineffective transition to practice can lead to ineffective delivery of quality health care. ${ }^{[20]}$ The participants provided insight into how they perceived their clinical and academic preparedness to function as a NP was related to the additional training they received in the internship. The novice NPs interviewed were not as overwhelmed in their first new role, although they had prior RN experience. The internship was believed to help them transition earlier into practice. However, the participants indicated that more training would be beneficial. More research should be conducted with the goal of identifying more information that can provide insight into developing effective educational programs for NPs that will improve or enhance their assimilation into practice.

\section{CONFLicts OF INTEREST Disclosure}

The authors declare that there is no conflict of interest.

\section{REFERENCES}

[1] NP Facts. American Association of Nurse Practitioners; 2018 [cited 2017 Mar 29]. Available from: http: //www . aanp.org/images/ documents/about-nps/npfacts.pdf

[2] Jones M. Developing clinically savvy nursing students: an evaluation of problem-based learning in an associate degree program. Nurs Educ Perspect. 2008; 29(5): 278-283.

[3] Becker's Hospital Review Staff. The year ahead: 10 challenges that will shape hospital strategy. 2012. Available from: http: //www. beckershospitalreview.com

[4] Attride-Stirling J. Thematic networks: an analytic tool for qualitative research. Qual Res. 2001; 1: 385-405. https ://doi.org/10.117 7/146879410100100307

[5] Hart A, Macnee CL. How well are nurse practitioners prepared for practice: results of a 2004 questionnaire study. J Am Acad Nurse Pract. 2007; 19(1): 35-42. PMid:17214866 https ://doi .org/10 
$.1111 / \mathrm{j} .1745-7599.2006 .00191 . \mathrm{x}$

[6] Heitz LJ, Steiner SH, Burman ME. RN to FNP: a qualitative study of role transition. J Nurs Educ. 2004; 43(9): 416-420.

[7] Brown M, Olshansky E. From limbo to legitimacy: a theoretical model of the transition to the primary care nurse practitioner role. Nurs Res. 1997; 46(1): 46-51. https : //doi.org/10.1097/0000 6199-199701000-00008

[8] Jones J, Kotthoff-Burrell E, Kass-Wolff J, et al. Nurse practitioner graduates 'Speak Out' about the adequacy of their educational preparation to care for older adults: a qualitative study. J Am Assoc Nurse Pract. 2015; 27(12): 698-706. PMid:25767091 https: //doi.org/10.1002/2327-6924.12230

[9] Harris C. Bridging the gap between acute care nurse practitioner education and practice: the need for postgraduate residency programs. J Nurse Pract. 2014 May; 10(5): 331-336. https ://doi .org/10.1 016/j.nurpra.2014.03.003

[10] Dillon DL, Dolansky MA, Casey K, et al. Factors related to successful transition to practice for acute care nurse practitioners. AACN Adv Crit Care. 2016; 27(2): 173-182. PMid:27153306 https://doi.org/10.4037/aacnacc2016619

[11] Cohen M. A historical overview of the phenomenological movement. J Nurs Sch. 1987; 19(1): 31-34. https ://doi.org/10.1111/j 1547-5069.1987.tb00584.x

[12] Creswell, JW. Qualitative inquiry \& research design: Choosing among five approaches. 2nd ed. Thousand Oaks, CA: Sage; 2007.
[13] The National Council of State Boards of Nursing (NCSBN). 2015 National Nursing Workforce Study. Available from: https : //www . ncsbn.org/workforce.htm

[14] Colaizzi PF. Psychological research as the phenomenologist views it. In R. S. Valle \& M King (Eds.), Existential phenomenological alternatives for psychology. New York: Plenum; 1978.

[15] Lincoln Y, Guba E. Naturalistic Inquiry. Newbury Park, CA: Sage Publications; 1985.

[16] Speziale HJ, Carpenter DR. Qualitative research in nursing advancing the humanistic imperative. Philadelphia: Lippincott Williams \& Wilkins; 2007.

[17] Sorsa MA, Kiikkala I, Åstedt-Kurki P. Bracketing as a skill in conducting unstructured qualitative interviews. Nurse Researcher. 2015; 22(4): 8. PMid:25783146 https ://doi .org/10.7748/nr. 22.4. 8.e 1317

[18] Bays AM, Engelberg RA, Back AL, et al. Interprofessional communication skills training for serious illness: evaluation of a small-group, simulated patient intervention. J Palliat Med. 2014; 17(2): 159-166.

[19] Institute of Medicine. The Future of Nursing: Leading the Change, Advancing Health. Washington, DC: The National Academies Press; 2011.

[20] Hain D, Fleck L. Barriers to nurse practitioner practice that impact healthcare redesign. Online J Issues Nurs. 2014; 19(2): 2. 